\title{
Biomarker for energy intake
}

Citation for published version (APA):

Westerterp, K. (2017). Biomarker for energy intake: resting energy expenditure and physical activity. In D. A. Schoeller, \& M. S. Westerterp-Plantenga (Eds.), Advances in the Assessment of Dietary Intake CRC Press. https://doi.org/10.1201/9781315152288-11

Document status and date:

Published: 01/01/2017

DOI:

10.1201/9781315152288-11

Document Version:

Accepted author manuscript (Peer reviewed / editorial board version)

Document license:

CC BY-NC-ND

\section{Please check the document version of this publication:}

- A submitted manuscript is the version of the article upon submission and before peer-review. There can be important differences between the submitted version and the official published version of record.

People interested in the research are advised to contact the author for the final version of the publication, or visit the DOI to the publisher's website.

- The final author version and the galley proof are versions of the publication after peer review.

- The final published version features the final layout of the paper including the volume, issue and page numbers.

Link to publication

\footnotetext{
General rights rights.

- You may freely distribute the URL identifying the publication in the public portal. please follow below link for the End User Agreement:

www.umlib.nl/taverne-license

Take down policy

If you believe that this document breaches copyright please contact us at:

repository@maastrichtuniversity.nl

providing details and we will investigate your claim.
}

Copyright and moral rights for the publications made accessible in the public portal are retained by the authors and/or other copyright owners and it is a condition of accessing publications that users recognise and abide by the legal requirements associated with these

- Users may download and print one copy of any publication from the public portal for the purpose of private study or research.

- You may not further distribute the material or use it for any profit-making activity or commercial gain

If the publication is distributed under the terms of Article $25 \mathrm{fa}$ of the Dutch Copyright Act, indicated by the "Taverne" license above, 


\title{
11 Biomarker for Energy Intake Resting Energy Expenditure and Physical Activity
}

\author{
Klaas R. Westerterp
}

\section{CONTENTS}

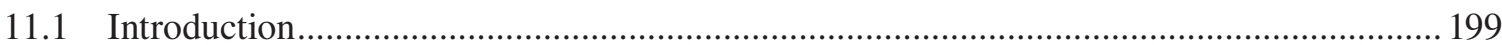

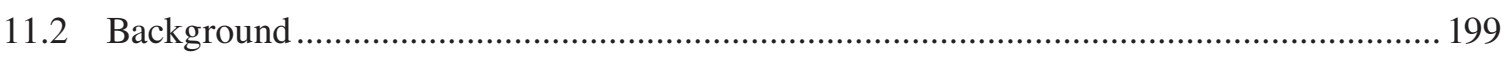

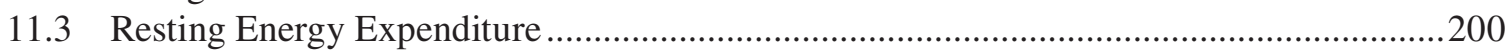

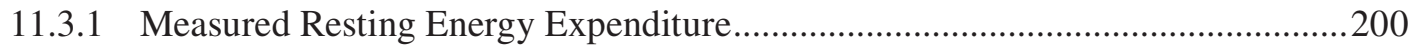

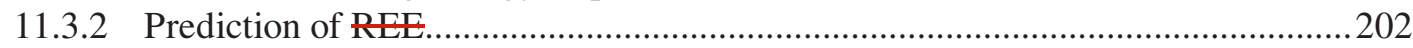

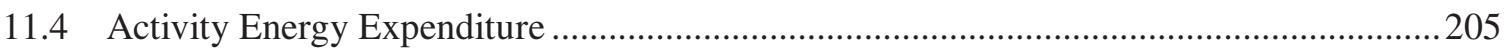

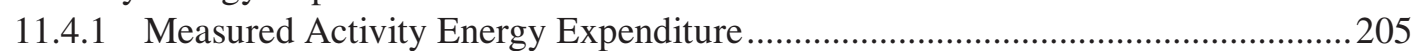

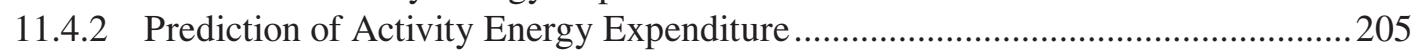

11.5 Applications of Energy Expenditure Biomarkers to Diet Assessment ...............................207

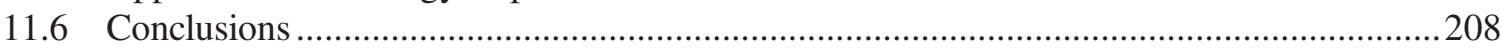

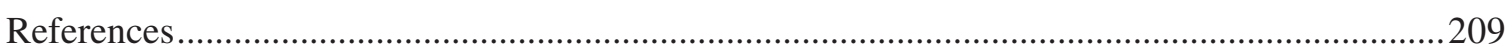

\subsection{INTRODUCTION}

Energy intake is a function of energy requirement as determined by resting energy expenditure and activity-induced energy expenditure. Resting energy expenditure can be measured or predicted with an equation based on weight, height, age, and gender of the subject. Activity-induced energy expenditure (AEE) can be estimated with an accelerometer for movement registration. The validity of these measures for estimating energy intake is presented with respirometry assessed resting energy expenditure and doubly-labeled water assessed total energy expenditure as a reference. Prediction of resting energy expenditure based on subject sex, weight, height, and age with equations is applicable for most subjects. For some ethnicities or for subjects with an exceptional physical activity level like athletes, measurement of body composition is indicated; to use a fat-free mass-based equation. For activity-induced energy expenditure, a valid sensor for body movement should allow explaining most of the variation as observed with the reference; doubly-labeled water assessed total energy expenditure.

\subsection{BACKGROUND}

Adult subjects maintain a balance between their energy intake and energy expenditure. The energy store of the body does not fluctuate much, as shown by the constancy of body weight and body composition. Thus, energy intake can be estimated from energy requirement to maintain energy balance, that is, to maintain body weight and body composition. Energy requirement is a function of energy expenditure for body maintenance or resting energy expenditure (REE) and of physical activity or AEE. Total energy expenditure consists of three components: REE, AEE, and the thermic effect of food (TEF) also known as diet-induced energy expenditure, where the latter is the smallest component (Figure 11.1). The thermic effect of food is determined by food intake and food 


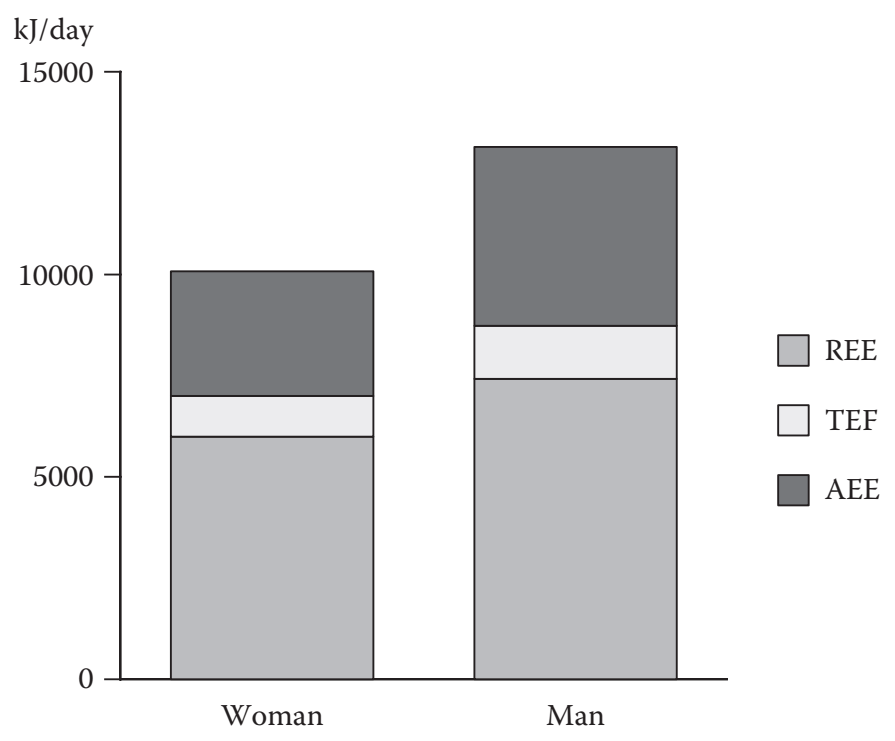

FIGURE 11.1 Total energy expenditure and the component's resting energy expenditure (REE), diet-induced energy expenditure (TEF), and activity-induced energy expenditure (AEE), for a typical adult woman and man.

composition. Reported TEF values for separate nutrients are $0 \%-3 \%$ for fat, $5 \%-10 \%$ for carbohydrate, 20\%-30\% for protein (Tappy 1996), and 10\%-30\% for alcohol (Acheson 1993). In healthy subjects with a mixed diet, TEF represents about $10 \%$ of the total amount of energy ingested over 24 hours. When a subject is in energy balance, where intake equals expenditure, TEF can be estimated as a fixed proportion of $10 \%$ of total energy expenditure (Westerterp 2004).

The reference technique for the assessment of REE and AEE is indirect calorimetry. In indirect calorimetry the energy production is calculated from oxygen consumption, carbon dioxide production, and urine-nitrogen loss. The basis of the calculation is the gaseous exchange and energy release from the metabolized carbohydrate, fat, and protein. For the measurement of REE, a subject is observed under standard conditions excluding TEF and AEE. For the measurement of AEE, the subject is observed under free-living conditions. Then, total energy expenditure is measured with the doubly-labeled water technique, based on the measurement of carbon dioxide production as described in the foregoing chapter, and AEE is derived from total energy expenditure adjusted for REE. Measurements of REE with indirect calorimetry allowed the development of prediction equations for REE based on subject characteristics including height, age, weight, and gender. The alternative for doubly-labeled water assessed AEE is an accelerometer for body movement registration as validated with doubly-labeled water assessed AEE as a reference.

The current chapter describes the assessment of energy intake based on the assessment of REE and AEE, where REE is estimated with a prediction equation and AEE is derived with doublylabeled water validated accelerometer for movement registration. Theory of measure, validation, protocol, and application are presented for the two components REE and AEE separately, followed by the combination of the two, as biomarker for energy intake.

\subsection{RESTING ENERGY EXPENDITURE}

\subsubsection{Measured Resting Energy Expenditure}

The energy expenditure for body maintenance or REE is, generally, the largest component of TEE (Black et al. 1996). It is defined as the energy expenditure to maintain and preserve the integrity of vital functions. The measurement of REE under the basal conditions must meet four conditions: (1) the subject is awake, (2) is measured in a thermoneutral environment to avoid energy expenditure for 
the maintenance of body temperature, (3) is fasted long enough to eliminate TEF, and (4) is in rest to eliminate AEE. To perform accurate measurement of REE, one usually adopts an in-patient protocol. A subject stays overnight in the research facility where food intake and physical activity are strictly controlled, and REE is measured directly after waking up in the morning. A 10-12 hour fast before REE measurement is the accepted procedure to eliminate TEF. Thus, when REE is measured at 7.00 AM, subjects should be fasted from about 8.00 PM the day before. High intensity exercise should be prevented on the day before REE measurement. An outpatient protocol, where subjects are transported by car or public transport to the laboratory after spending the night at home produces sufficiently reproducible results when subjects are carefully instructed and behave accordingly (Adriaens et al. 2003).

A typical protocol for a REE measurement with a ventilated-hood system takes 30 minutes. To eliminate effects of subject habituation to the testing procedure, the respiratory measurements over the first 10 minutes are discarded and the following 20 minutes are used to calculate REE. The criterion for the chosen time interval is the reproducibility of the calculated REE value. Longer measurements tend to result in higher values because subjects become restless. Reproducibility of REE measurement is influenced by the within-machine variability of the ventilated-hood system (Adriaens et al. 2003). Calibration procedures include standard gases covering the span of the oxygen and carbon dioxide analyzers, and a standard volume for calibration of the hood ventilation. Overall performance of a ventilated-hood system can be checked with methanol burning (Schoffelen et al. 1997). Methanol $99.8 \%$ is combusted by using a gas burner, placed on a calibrated balance under the hood. The methanol burner is set at a burning rate equivalent to the oxygen consumption and carbon dioxide production of the average subject and the burning time is comparable to a typical hood measurement.

Resting energy expenditure is usually compared between subjects by standardizing to an estimate of metabolic body size, where fat-free mass is the main predictor (Cunningham 1991). The reliable way of comparing REE data is by regression analysis. REE should never be divided by the absolute fat-free mass value, because the relationship between energy expenditure and fat-free mass has an axes intercept that is significantly different from zero (Figure 11.2). The smaller the fat-free mass the higher the REE/kg, and thus the REE per $\mathrm{kg}$ fat-free mass is on average higher in women with a lower fat-free mass compared to men. When fat-free mass, fat mass and gender are included as covariates in a regression analysis; gender does not come out as a significant contributor to the explained variation (Westerterp 1999).

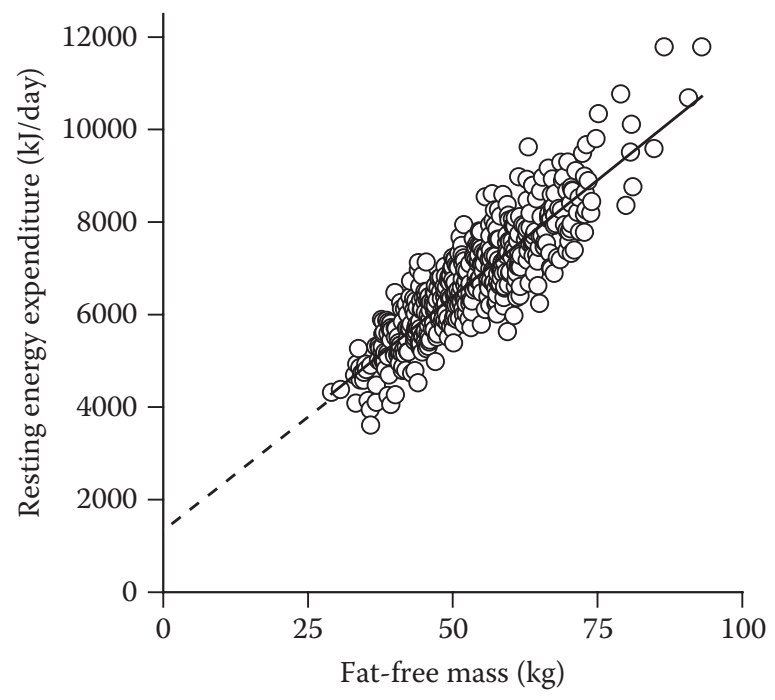

FIGURE 11.2 Resting energy expenditure plotted as a function of fat-free mass with the linear regression showing a significant positive intercept. (From Speakman, J. R. and K. R. Westerterp. Am. J. Clin. Nutr, 92, 826-834, 2010.) 


\subsubsection{Prediction of ReE}

Although fat-free mass is the main predictor of REE, fat-free mass is not routinely used for the prediction of REE as measurement of fat-free mass is complicated. Thus prediction equations for REE were developed, based on subject sex, weight, height, and age. The most commonly used prediction equations are Harris Benedict (Harris and Benedict 1919), Food and Agricultural Organization (FAO/WHO/UNU 1985), Owen (Owen et al. 1986 and 1987), and Mifflin (Mifflin et al. 1990). An equation to predict REE from subject sex, weight, height, and age is based on an estimation of fatfree mass from subject sex, weight, height, and age, as shown below.

To simulate changes in body weight in response to a change in energy intake or physical activity, we developed a prediction equation for REE from subject sex, weight, height, and age with data from 190 subjects, of which 105 women, body mass 38 to $215 \mathrm{~kg}$, height 1.30 to $2.05 \mathrm{~m}$, and age 19 to 95 year (Westerterp et al. 1995). First fat-free mass (FFM) was predicted from subject sex, weight, height, and age, and then the FFM was used in a prediction equation for REE:

For women: FFM $(\mathrm{kg})=0.218 \mathrm{BM}(\mathrm{kg})+27.392$ height $(\mathrm{m})-0.074$ age $(\mathrm{y})-12.5 ; \mathrm{r}^{2}=0.81$;

For men: FFM $(\mathrm{kg})=0.292 \mathrm{BM}(\mathrm{kg})+34.009$ height $(\mathrm{m})-0.105$ age $(\mathrm{y})-18.4 ; \mathrm{r}^{2}=0.79$.

The equations show that women have relative less FFM per kg body mass than men, taller subjects have more FFM, and FFM decreases with increasing age.

As shown below, prediction equations for REE from subject sex, weight, height, and age are similar to prediction equations for FFM. Here, the Harris Benedict equation and the Owen equation were derived by combining the original data for women and men. The WHO-prediction uses separate equations for women and men and for subjects aged 18-30, 30-60, and over 60 year.

AQ 1 Harris Benedict: 231 subjects, 99 women, 6 with BMI $>30 \mathrm{~kg} / \mathrm{m}^{2}$, age $18-74$ year;

$\operatorname{REE}(\mathrm{kJ} / \mathrm{d})=49.0 \mathrm{BM}(\mathrm{kg})+23.5$ height $(\mathrm{m})-23.4$ age $(\mathrm{y})+448 \mathrm{Sex}-218 ; \mathrm{r}^{2}=0.80$;

Owen: 104 subjects, 44 women, 32 with BMI $>30 \mathrm{~kg} / \mathrm{m}^{2}$, age 18-82 year;

$\operatorname{REE}(\mathrm{kJ} / \mathrm{d})=33.7 \mathrm{BM}(\mathrm{kg})+18.5$ height $(\mathrm{m})-14.9$ age $(\mathrm{y})+1200 \mathrm{Sex}+590 ; \mathrm{r}^{2}=0.71$;

Mifflin: 498 subjects, 247 women, 234 with BMI $>30 \mathrm{~kg} / \mathrm{m}^{2}$, age 19-78 year;

$\operatorname{REE}(\mathrm{kJ} / \mathrm{d})=41.8 \mathrm{BM}(\mathrm{kg})+26.2$ height $(\mathrm{m})-20.6$ age $(\mathrm{y})+695 \mathrm{Sex}-674 ; \mathrm{r}^{2}=0.71$;

Where for women $\mathrm{Sex}=0$ and for $\operatorname{men} \mathrm{Sex}=1$.

WHO: 4814 subjects, 1239 women, including adults of different weight for height, age $>18$ year.

\begin{tabular}{lll}
\hline Women & 18-30 year & REE $(\mathrm{kJ} / \mathrm{d})=55.6 \mathrm{BM}(\mathrm{kg})+1397.4$ height $(\mathrm{m})+146$ \\
& 30-60 year & $\operatorname{REE}(\mathrm{kJ} / \mathrm{d})=36.4 \mathrm{BM}(\mathrm{kg})-104.6$ height $(\mathrm{m})+3619$ \\
& $>60$ year & $\operatorname{REE}(\mathrm{kJ} / \mathrm{d})=38.5 \mathrm{BM}(\mathrm{kg})+2665.2$ height $(\mathrm{m})-1264$ \\
Men & 18-30 year & $\operatorname{REE~}(\mathrm{kJ} / \mathrm{d})=64.4 \mathrm{BM}(\mathrm{kg})-113.0$ height $(\mathrm{m})+3000$ \\
& 30-60 year & $\operatorname{REE~}(\mathrm{kJ} / \mathrm{d})=47.2 \mathrm{BM}(\mathrm{kg})+66.9$ height $(\mathrm{m})+3769$ \\
& $>60$ year & REE $(\mathrm{kJ} / \mathrm{d})=36.8 \mathrm{BM}(\mathrm{kg})+4719.5$ height $(\mathrm{m})-4481$
\end{tabular}


The four mostly used REE prediction equations as presented above have been evaluated extensively. Prediction accuracy is usually defined as the percentage of individuals in the study group whose REE is predicted to within plus or minus $10 \%$ of the measured REE (Frankenfield et al. 2005; Neelemaat et al. 2012; Rao et al. 2012; Siervo et al. 2014; Ten Haaf and Weijs 2014; Weijs 2008; Weijs and Vansant 2010). The more an individual shares characteristics with the group of people from whom the equation was developed the better the estimate. The Harris Benedict and Mifflin equation provided accurate estimates over a wide range of body mass index. Above body mass index $45 \mathrm{~kg} / \mathrm{m}^{2}$, the WHO equation should not be used in this extremely obese group (Weijs and Vansant 2010). The Mifflin equation was associated with the largest error in subjects older than 60 year (Siervo et al. 2014). In older and malnourished patients, the WHO equation came out best (Neelemaat et al. 2012).

As an example, Figure 11.3 presents the frequency distribution for percentage differences between predicted REE with the Harris Benedict, WHO, Owen, and Mifflin equation and

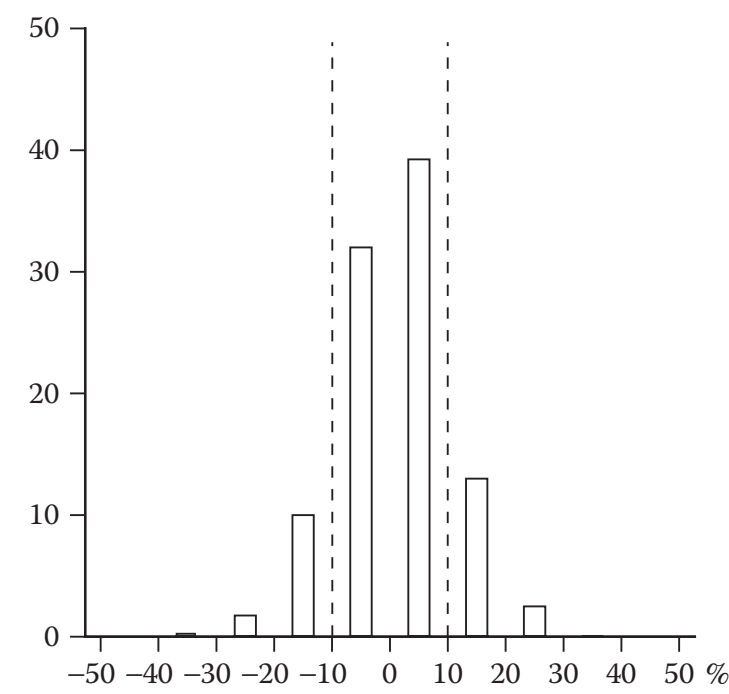

(a)

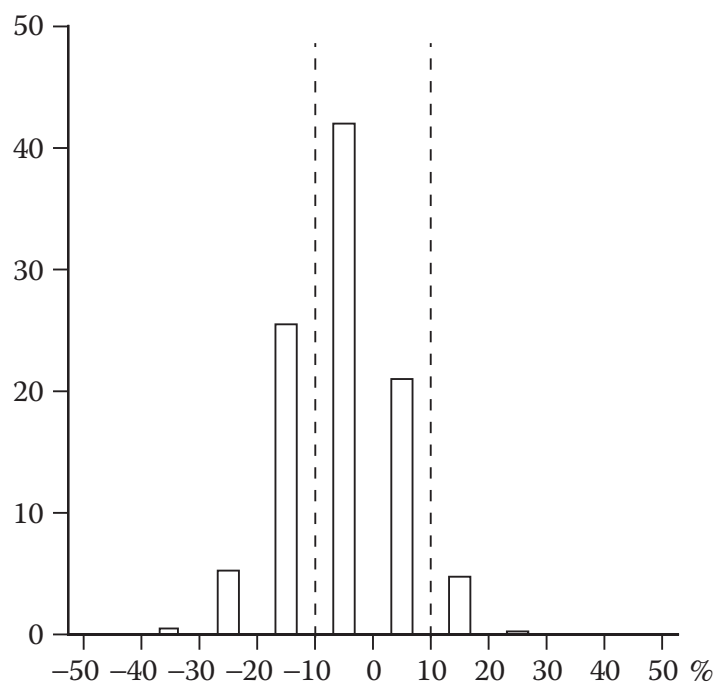

(c)

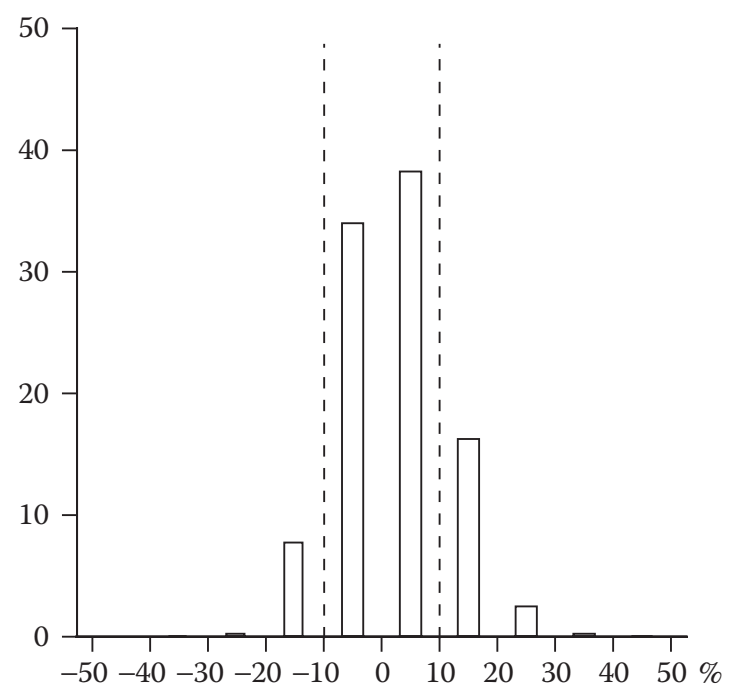

(b)

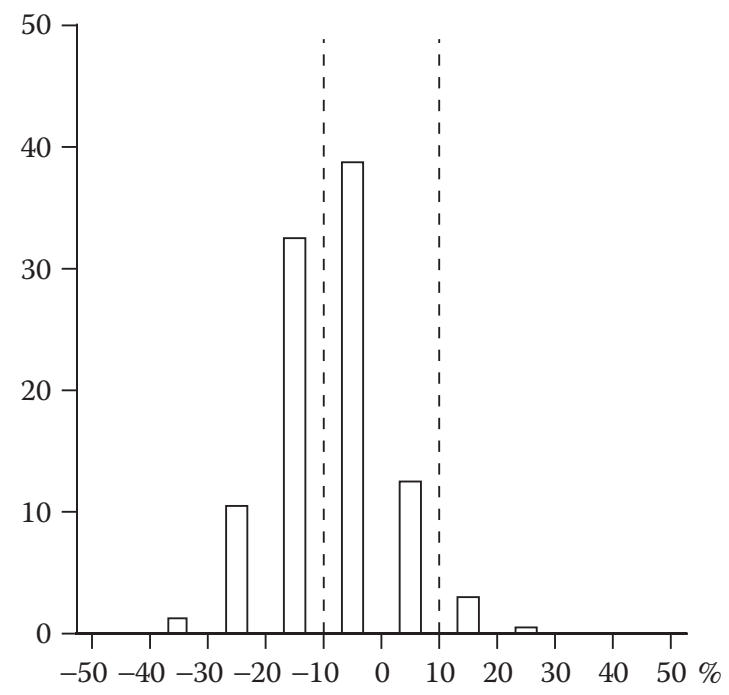

(d)

FIGURE 11.3 Frequency distribution for percentage differences between predicted and measured resting energy expenditure for 529 subjects (From Speakman, J. R. and K. R. Westerterp. Am. J. Clin. Nutr, 92, 826-834, 2010.): (a) prediction equation Harris et al. (1919); (b) prediction equation WHO/FAO/UNU (1985); (c) prediction equation Owen et al. (1986, 1987); and (d) prediction equation Mifflin et al. (1990). 
measured REE for 556 subjects, 234 women, 95 with BMI $>30 \mathrm{~kg} / \mathrm{m}^{2}$, age 18 to 96 year (data from Speakman and Westerterp 2010). In this reference group, covering a large age span, the Harris Benedict and WHO equation did best with more than $70 \%$ of the subjects within the defined range of plus or minus $10 \%$ of the measured REE, whereas with the Mifflin equation this accuracy level was reached for only $50 \%$ of the subjects. The Mifflin equation was derived from a population with nearly 50\% obese subjects and apparently does not apply for this reference population with less than $20 \%$ obese subjects.

Additional subject characteristics to take into account for the prediction of REE are ethnicity affecting body build and special behavior affecting body composition, like athletic performance. Clear examples of differences in body build affecting the accuracy of the generally Caucasianbased prediction equations for REE are Asian Indians. Where the Owen and Mifflin equation were appropriate for the prediction of REE in Chinese (Rao et al. 2012), Caucasian-based prediction equations systematically overestimate REE in South Asian Indians (Wouters-Adriaens et al. 2008; Wulan et al. 2010). South Asian Indians have a higher percentage of body fat at a lower body mass index compared to Caucasians. The high body fat percentage at low body mass index can be partly explained by differences in body build, that is, differences in trunk-to-leg-length ratio and differences in slenderness and muscularity (Deurenberg et al. 2002). There are no differences in REE between South Asian Indians and Caucasians after adjustment for differences in fat-free mass (Wouters-Adriaens et al. 2008). Thus, South Asian Indians are an exceptional population requiring a population-specific equation for predicting REE from subject sex, weight, height, and age. Similarly, muscularity and fat-free mass can be affected by athletic performance. Then, the Cunningham equation (Cunningham 1991) based on fat-free mass is the first choice for the prediction of REE. Alternatively, there are equations based on subject sex, weight, height, and age for athletes like an equation derived from REE measurement in a group of young recreational athletes (Ten Haaf and Weijs 2014):

90 subjects, 37 women, age $18-35$ year;

$\operatorname{REE}(\mathrm{kJ} / \mathrm{d})=49.940 \mathrm{BM}(\mathrm{kg})+2459.1$ height $(\mathrm{m})-34.0$ age $(\mathrm{y})+799 \mathrm{Sex}+122$;

Where for women Sex $=0$ and for men $\operatorname{Sex}=1$.

A special case, where even the Cunningham equation based on fat-free mass does not produce accurate estimates for REE are elite athletes. Sjödin et al. (1996) measured in top international cross-country skiers that REE values $16 \%$ higher than that predicted from the weight-based WHO equation and $12 \%$ higher than in sedentary fat-free mass matched control subjects.

Prediction equations for REE based on subject sex, weight, height, and age are applicable for most subjects, where for some situations measurement of body composition is indicated as described. An example where indirect calorimetry measurement of REE shows a systematic difference with predicted values is in subjects after weight loss. Underfeeding induces a reduction in REE belowpredicted values, as based on the new body composition reached after underfeeding-induced weight loss (Camps et al. 2013; Major et al. 2007; Rosenbaum et al. 2008; Schwartz et al. 2012). The REE reduction, adjusted for changes in body composition, ranges between 5\% and slightly more than 10\% of the initial value, depending on time interval after the intervention. Van Gemert et al. observed an average reduction of $12 \%$ at three months after the start of weight loss and of $6 \%$ when weight loss was maintained for more than three years (Van Gemert et al. 1998).

In summary, prediction of REE based on subject sex, weight, height, and age with equations as presented from Harris and Benedict and from WHO/FAO/UNU give estimates within $10 \%$ for most subjects. For some ethnicities like South Asian Indians or subjects with an exceptional physical activity level like athletes, measurement of body composition is indicated; to use a fat-free mass-based equation. In some situations, only an indirect calorimetry measurement guarantees an estimate within $10 \%$. 


\subsection{ACTIVITY ENERGY EXPENDITURE}

\subsubsection{Measured Activity Energy Expenditure}

Activity energy expenditure is the most variable component of TEE. Activity energy expenditure is determined by body movement and by the mass moved, that is, body mass, where body movement or physical activity level varies between individuals. The indicated method for the assessment of body movement in daily life is a motion sensor. Motion sensors for the assessment of body movement recently evolved from mechanical devices like pedometers to miniature electronic triaxial accelerometers for movement registration (Plasqui et al. 2013; Plasqui and Westerterp 2007).

Accelerometer-based activity monitors quantify physical activity by measuring the acceleration of the human body during movement. Accurate and unobtrusive measurements of physical activity are achieved only when the accelerometer has certain physical and technical characteristics in terms of dimensions, weight, and amount of information processed and recorded. Considering that there is a trade-off between the energy consumption, portability, and performance (quality or quantity of information collected) of an activity monitor, the design largely determines the degree of accuracy and unobtrusiveness. Accurate measurements of physical activity can be achieved when the acceleration signal from the body is collected at a frequency sufficient to ensure that the full range of human motions is captured. The frequency content of the acceleration of the body during physical activity varies according to the measurement location. At the waist level, $95 \%$ of the variability of the acceleration signal can be determined by harmonics with $10 \mathrm{~Hz}$. The amplitude does not exceed $6 \mathrm{~g}$ in magnitude $\left(1 \mathrm{~g}=9.8 \mathrm{~m} / \mathrm{s}^{2}\right.$ ) (Antonsson and Mann 1985; Bouten et al. 1997). Thus, according to the Nyquist theorem, an accurate accelerometer should collect acceleration data at a sampling frequency of $20 \mathrm{~Hz}$. Furthermore, it should be able to process the acceleration signal to filter out noise and extract relevant characteristics from the acceleration pattern so as to describe physical activity.

Nowadays, there are many accelerometer-based sensors for monitoring body movement available, including sensors incorporated in body worn devices like wristwatches and smartphones. The capability of motion sensors to predict AEE is usually tested during standardized activities like walking and running on a treadmill under laboratory conditions, generally showing good performance (Plasqui and Westerterp 2007). The ultimate test is a validation over one or more weeks under free-living conditions, where AEE is derived from simultaneous measurement of TEE with doubly-labeled water in combination with a measurement of REE. Then, only a few usable sensors remain so far (Westerterp 2014). Many devices only produce values for total energy expenditure based on subject sex, weight, height, age, and measured body acceleration. Unfortunately, the validity of this method is questionable. The outcome often is a function of proprietary equations. Thus, the user has no information on the equation for REE adopted, based on subject sex, weight, height, and age. In addition, only for a few devices, the correlation of the outcome for total energy expenditure with the measured doubly-labeled water assessed total energy expenditure as reference is driven by measured body acceleration (Plasqui and Westerterp 2007).

\subsubsection{Prediction of Activity Energy Expenditure}

Approaches to prediction of AEE can be broken into two categories: those that estimate a multiple of REE and those that estimate AEE directly. The former way of expressing the physical activity level of a subject is by expressing TEE as a multiple of REE, adjusting TEE for differences in maintenance metabolism (PAL = TEE/REE; WHO/FAO/UNU 1985). The limits of TEE are established at around 1.2 REE for nonambulatory subjects to 4.5 REE for elite endurance athletes (Black et al. 1996). FAO/WHO/UNU classified the physical activity level of a subject in three categories (FAO/ WHO/UNU 2004). The physical activity for sedentary and light activity lifestyles ranges between 1.40 and 1.69 , for moderately active or active lifestyles between 1.70 and 1.99 , and for vigorously active lifestyles between 2.00 and 2.40. Thus, for most subjects REE is the largest component of 
TEE as stated already in the section on REE. Activity energy expenditure is only one third of TEE at a PAL of 1.70, the value for a moderately active subject, as shown below by examples of a typical woman and man.

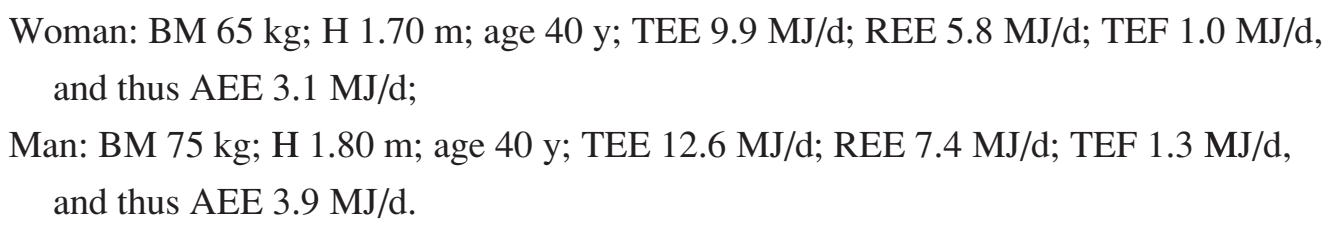

Variation in AEE between subjects can be partly explained by body mass, age, and sex. As mentioned above, AEE is higher for the same body movement in a subject with a higher body mass. Thus, AEE is generally higher in heavier subjects. Activity energy expenditure peaks when adult weight is reached and then gradually declines with increasing age. Thus, it seems that AEE is highest during the reproductive years (Heitmann et al. 2012). In addition, there is a systematic sex difference. Mainly due to the fact that men are generally larger than women, AEE tends to be higher in men than in women while differences in PAL, adjusting TEE of differences in body size, are negligible (Black et al. 1996). Body mass, age, and sex are included as significant parameters in a prediction equation for AEE as derived from data from 556 subjects, 234 women, 95 with BMI $>30 \mathrm{~kg} / \mathrm{m}^{2}$, age 18-96 year (data from Speakman and Westerterp 2010).

$$
\begin{aligned}
& \operatorname{AEE}(\mathrm{kJ} / \mathrm{d})=24.3 \mathrm{BM}(\mathrm{kg})-39.4 \text { age }(\mathrm{y})+1172 \mathrm{Sex}+3064 ; \mathrm{r}^{2}=0.38 \\
& \text { Where for women } \operatorname{Sex}=0 \text { and for } \operatorname{men} \operatorname{Sex}=1
\end{aligned}
$$

Comparing the prediction of REE and AEE from subject characteristics, the explained variation for AEE is only half the explained variation for REE. Body movement, as the main determinant of AEE, has to be included to get to more accurate predictions of AEE.

Prediction equations for AEE from motion sensor-assessed body movement should have an explained variation HIGHER than $40 \%$, what can be reached already by including subject body mass, age, and sex in the equation as shown above. Thus, out of 11 sensors validated under freeliving conditions, most showed a poor performance and only three showed sufficient validity (Westerterp 2014). They explained 50\%-70\% of the variation in AEE, still leaving at least 30\% of the variation unexplained. Further improvement will be reached with monitors allowing the assessment of activity type. The relation between body movement and AEE is different for activities like walking and cycling. Identification of activity types improved the assessment of AEE compared with overall unidentified body movement only (Bonomi and Westerterp 2012; Van Hees et al. 2009).

Physical activity and thus AEE shows short-term variation, from day-to-day, and long-term variation in relation to season. In a climate with adverse weather conditions in winter and more friendly weather in summer, subjects are more homebound, and thus less physically active in winter, and more outgoing and thus more physically active in summer (Figure 11.4). In the Netherlands, physical activity level was lower in winter with ambient temperatures around $5^{\circ} \mathrm{C}$ than in summer with ambient temperatures around $20^{\circ} \mathrm{C}$ (Plasqui and Westerterp 2003). However, seasonal differences were small and the higher AEE in summer was partly compensated by a lower REE and thus total energy expenditure was not significantly different between seasons, as observed in a study on the effects of seasonal changes in physical activity and energy requirements in the United Kingdom AQ 3 (Haggarty et al. 1994).

In summary, prediction equations based on subject weight and body movement can explain $50 \%-70 \%$ of the variation in AEE, when choosing a valid sensor for body movement. 


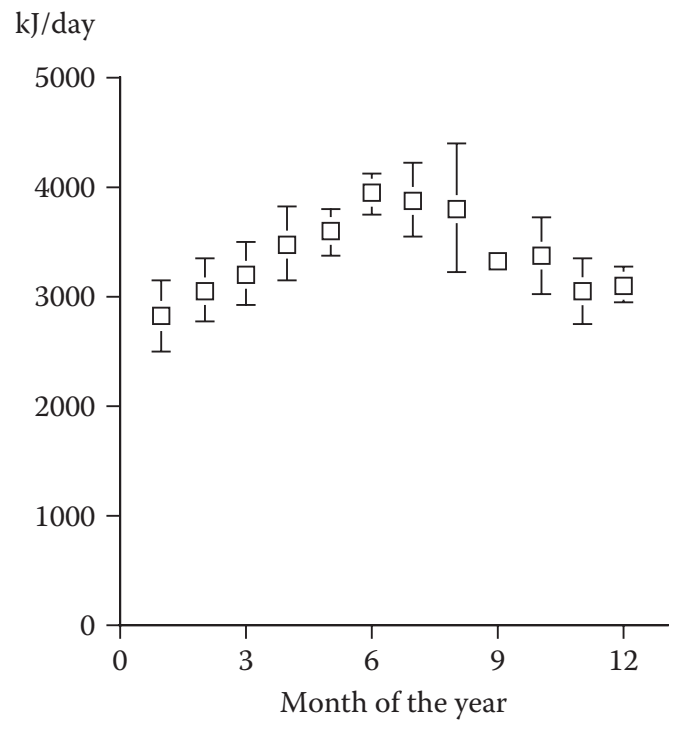

FIGURE 11.4 Annual pattern of activity-induced energy expenditure of a typical individual living in the Netherlands as derived from an accelerometer for movement registration. Monthly values are averages with SD over a seven-year interval.

\subsection{APPLICATIONS OF ENERGY EXPENDITURE BIOMARKERS TO DIET ASSESSMENT}

Resting energy expenditure and activity energy expenditure as biomarker intake one of the applications of resting energy expenditure and activity energy expenditure as biomarker of intake is the identification of underreporters of energy intake (EI) with the Goldberg cut off (Goldberg et al. 1991). Reported intake is expressed as a multiple of REE and the ratio should be higher than the PAL value for a sedentary lifestyle. However, excluding underreporters by excluding subjects reporting unlikely low intake does not imply reported that intake figures of the remaining subjects are valid. When a subject with an REE of $6 \mathrm{MJ} / \mathrm{d}$ reports an intake of $10 \mathrm{MJ} / \mathrm{day}$, the EI/REE figure is with a value 1.7 well above the value of 1.4 to 1.6 for a sedentary lifestyle. When the subject has an active lifestyle with a PAL of 2.0, energy intake should be approximately two times REE and equals $12 \mathrm{MJ} /$ day. Thus, a reported intake of $10 \mathrm{MJ} /$ day for this subject is $20 \%$ lower than their habitual intake. The indicated method to identify not only underreporters but also misreporters, in general, is by comparing EI/REE with a PAL figure derived from REE and AEE.

A first evaluation of reported energy intake by using calculated expenditure from REE and AEE was reported by Goris et al. (2001). The study was performed in 24 subjects, 12 women, age 55-65 year, and body mass index 19 to $33 \mathrm{~kg} / \mathrm{m}^{2}$. Energy intake was reported with a seven-day dietary record and energy expenditure was calculated from REE estimated with the WHO equation (FAO/WHO/UNU 1985) and AEE estimated with a doubly-labeled water validated accelerometer. Simultaneously, energy expenditure was measured with the doubly-labeled water method, as described in the foregoing chapter, as a reference. Reported intake of $9.0 \pm 2.1 \mathrm{MJ} / \mathrm{day}$ was significantly lower than calculated expenditure of $10.8 \pm 1.7 \mathrm{MJ} / \mathrm{d}(\mathrm{p}<0.001)$ and measured energy expenditure of $11.3 \pm 2.3 \mathrm{MJ} /$ day $(\mathrm{p}<0.001)$. The percentage of underreporting derived from calculated and measured energy expenditure was similar, showing the validity of the combination of estimated REE and AEE as a biomarker of energy intake.

An example of the application of calculated energy expenditure to evaluate estimated energy intake is a study in Danish children (Biloft-Jensen et al. 2013). Energy intake, recorded with web-based dietary assessment software, was not different from calculated expenditure at group level. At the individual level, $20 \%$ of the children were classified as overreporters and $20 \%$ were 


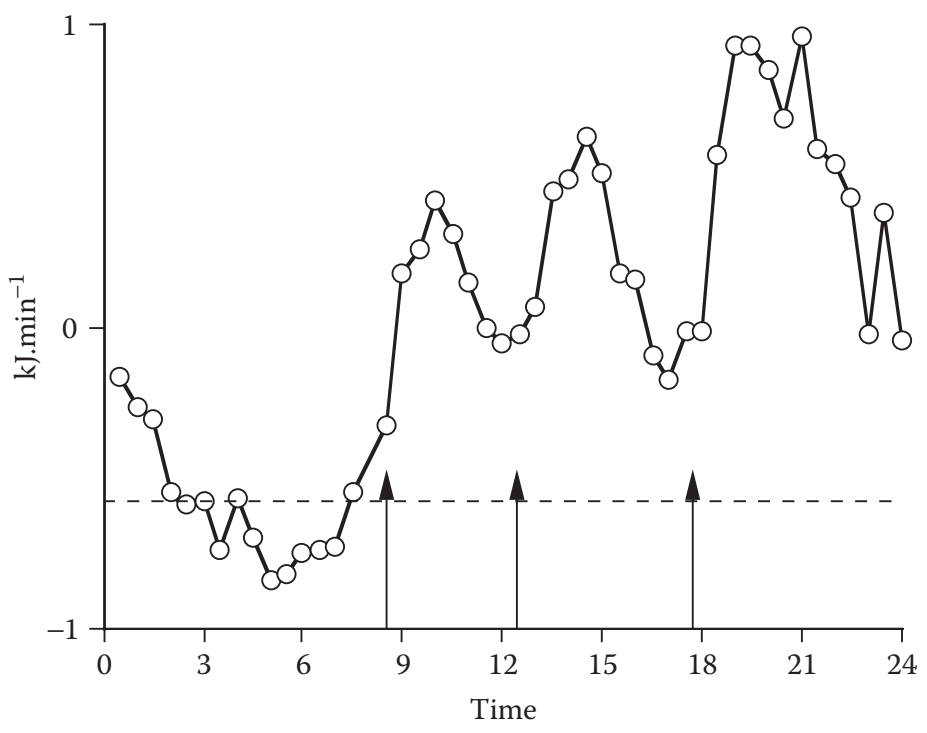

FIGURE 11.5 The diurnal pattern of resting energy expenditure including the thermic effect of food minus the level of basal metabolic rate (dotted line); subjects followed a protocol with fixed meal times (arrows) and were allowed to sleep from 23.00 to 07.00. (From Westerterp, K. R. Nutr Metab 1, 5, 2004.)

classified as underreporters. Interestingly, underreporters were more likely than both acceptable and overreporters to report that illness, due to a flu epidemic, affected eating during the recording period. Similarly, overreporting might reflect real overeating to compensate for a flu-induced reduction of intake just before the reporting interval. Thus, reported intake might be different from calculated expenditure for other reasons than misreporting as well. However, in healthy subjects, intake can be assumed to match expenditure over observation intervals of minimally one week (Edholm et al. 1955).

A point of discussion is whether energy intake estimated from REE and AEE as described includes TEF, as third component of total energy expenditure. The thermic effect of food peaks after meals during the active part of the day and is excluded from REE when REE is measured or predicted as described above. Resting energy expenditure including TEF shows a diurnal pattern, increasing above basal metabolic rate at breakfast and decreasing again below basal metabolic rate after midnight when asleep (Figure 11.5). In adults, overnight metabolic rate is equivalent to basal metabolic rate or REE as measured or estimated with the prediction equations described. Overnight metabolic rate is lower than basal metabolic rate in children and higher in older adults (WoutersAdriaens et al. 2006). Valenti at al. (2016) showed an inverse association of overnight metabolic rate with quality sleep, explaining the age-related increase in overnight metabolic rate. Physical activity as measured with a doubly-labeled water validated accelerometer for movement registration includes TEF when activity is expressed as PAL. Thus all components of energy expenditure are included in the estimate of energy intake when measured or estimated REE is multiplied with an accelerometer derived PAL value.

\subsection{CONCLUSIONS}

The assessment of energy intake with REE and AEE as biomarkers of dietary energy intake requires minimal information. REE is measured or estimated from an equation based on subject sex, weight, height, and age; AEE is measured with a doubly-labeled water validated accelerometer for movement registration. The easiest way to estimate habitual energy intake for weight maintenance from REE and AEE is the application of a device producing values for total energy expenditure based on subject sex, weight, height, age, and measured body acceleration. Unfortunately, the validity of most 
devices is questionable. The outcome often is a function of proprietary equations. Thus, the user has no information on the equation for REE adopted, based on subject sex, weight, height, and age. When estimation energy intake from subject sex, weight, height, age, and body acceleration, it is suggested to estimated REE and AEE separately by choosing the REE prediction equation, optimal for the population of study, in combination with measured AEE with a valid sensor for body movement.

\section{REFERENCES}

Acheson, K. J. 1993. Influence of autonomic nervous system on nutrient-induced thermogenesis in humans. Nutrition 9: 373-380.

Adriaens, M. P., P. F. Schoffelen, and K. R. Westerterp. 2003. Intra-individual variation of basal metabolic rate and the influence of daily habitual physical activity before testing. Br. J. Nutr. 90: 419-423.

Antonsson, E. K. and R. W. Mann. 1985. The frequency content of gait. J. Biomech. 18: 39-47.

Biloft-Jensen, A., M. F. Hjorth, E. Trolle, et al. 2013. Comparison of estimated energy intake using Web-based dietary assessment software with accelerometer-determined energy expenditure in children. Food Nutr. Res. 57.

Black, A. E., W. A. Coward, T. J. Cole, and A. M. Prentice. 1996. Human energy expenditure in affluent societies: An Analysis of 574 doubly-labelled water measurements. Eur. J. Clin. Nutr. 50: 72-92.

Bonomi, A. G. and K. R. Westerterp. 2012. Advances in physical activity monitoring and lifestyle interventions in obesity: A review. Int. J. Obes. 36: 167-177.

Bouten, C. V., K. T., Koekoek, M. Verduin, R. Kodde, and J. D. Janssen. 1997. A triaxial accelerometer and portable data processing unit for the assessment of daily physical activity. IEEE T Biomed Eng 44: $136-147$.

Camps, S. G., S. P. Verhoef, and K. R. Westerterp, 2013. Weight loss, weight maintenance and adaptive thermogenesis. Am. J. Clin. Nutr. 97: 990-994.

Cunningham, J. J. 1991. Body composition as a determinant of energy expenditure: A synthetic review and a proposed general prediction equation. Am. J. Clin. Nutr. 54: 963-969.

Deurenberg, P., M. Deurenberg-Yap, and S. Guricci. 2002. Asians are different from Caucasians and from each other in their body mass index/body fat per cent relationship. Obes. Rev. 3: 141-146.

Edholm, O. G., J. G. Fletcher, E. M. Widdowson, and R. A. McCance. 1955. The energy expenditure and food intake of individual men. Br. J. Nutr. 9: 286-300.

Food and Agricultural Organization/World Health Organization/United Nations University. 1985. Energy and protein requirements. Report of a joint FAO/WHO/UNU expert consultation. World Health Organization technical report series 724. Geneva, Switzerland.

Food and Agricultural Organization/World Health Organization/United Nations University. 2004. Human energy requirements. Rome: FAO Food and nutrition report series 1.

Frankenfield, D., L. Roth-Yousey, and C. Compher, 2005. Comparison of prediction equations for resting metabolic rate in healthy non obese and obese adults: A systematic review. J. Am. Diet. Assoc. 105: $775-789$.

Goldberg, G. R., A. E. Black, S. A. Jebb, et al. 1991. Critical evaluation of energy intake data using fundamental principles of energy physiology: 1 . Derivation of cut-off limits to identify under-recording. Eur. J. Clin. Nutr. 45: 569-581.

Goris, A. H., E. P. Meijer, A. Kester, and K. R. Westerterp. 2001. Use of a triaxial accelerometer to validate reported food intakes. Am. J. Clin. Nutr. 73: 549-553.

Haggarty, P., G. McNeill, M. K. Manneh, L. Davidson, E. Milne, G. Duncan, and J. Ashton. 1998. The influence of exercise on the energy requirements of adult males in the UK. Br. J. Nutr. 72: 799-813.

Harris, J. A. and F. G. Benedict. 1919. A biometric study of basal metabolism in man. Publication no. 297. Washington DC: Carnegie Institute of Washington.

Heitmann, B. L., K. R. Westerterp, R. J. Loos, et al. 2012. Obesity: Lessons from evolution and the environment. Obes. Rev. 13: 910-922.

Major, G. C., E. Doucet, P. Trayhurn, A. Astrup, and A. Tremblay. 2007. Clinical significance of adaptive thermogenesis. Int. J. Obes. 31: 204-212.

Mifflin, M. D., S. T. St Jeor, L. A. Hill, B. J. Scott, S. A. Daugherty, and Y. O. Koh. 1990. A new predictive equation for resting energy expenditure in healthy individuals. Am. J. Clin. Nutr. 51: 241-247.

Neelemaat, F., M. A. Van Bokhorst-de van der Schueren, A. Thijs, J. C. Seidell, and P. J. Weijs. 2012. Resting energy expenditure in malnourished older patients at hospital admission and three months after discharge: Predictive equations versus measurements. Clin. Nutr. 31: 958-966. 
Owen, O. E., E. Kavle, R. S. Owen, et al. 1986. A reappraisal of the caloric requirements in healthy women. Am. J. Clin. Nutr. 44: 1-19.

Owen, O. E., J. L. Hollup, D. A. D”Alessio, et al. 1987. A reappraisal of the caloric requirements of men. Am. J. Clin. Nutr. 46: 875-885.

Plasqui, G., A. G. Bonomi, and K. R. Westerterp. 2013. Daily physical activity assessment with accelerometers: New insights and validation studies. Obes. Rev. 14: 451-462.

Plasqui, G. and K. R. Westerterp. 2003. Seasonal variation in total energy expenditure and physical activity in Dutch young adults. Obes. Res. 12: 688-694.

Plasqui, G. and K. R. Westerterp. 2007. Physical activity assessment with accelerometers: An evaluation against doubly labeled water. Obesity 15: 2371-2379.

Rao, Z., X. Wu, B. Liang, M. Wang, and W. Hu. 2012. Comparison of five equations for estimating resting energy expenditure in Chinese young, normal weight healthy adults. Eur. J. Med. Res. 17: 26.

Rosenbaum, M., J. Hirsch, D. A. Gallagher, and R. L. Leibel. 2008. Long-term persistence of adaptive thermogenesis in subjects who have maintained a reduced body weight. Am. J. Clin. Nutr. 88: 906-912.

Schoffelen, P. F., K. R. Westerterp, W. H. Saris, and F. Ten Hoor. 1997. A dual-respiration chamber system with automated calibration. J. Appl. Physiol. 83: 2064-2072.

Schwartz, A., J. L. Kuk, G. Lamothe, and E. Doucet. 2012. Greater than predicted decrease in resting energy expenditure and weight loss: Results from a systematic review. Obesity 20: 2307-2310.

Siervo, M., S. Bertoli, A. Battezzati, et al. 2014. Accuracy of predictive equations for the measurement of resting energy expenditure in older subjects. Clin. Nutr. 33: 613-619.

Sjödin, A. M., A. H. Forslund, K. R. Westerterp, A. B. Andersson, J. M. Forslund, and L. M. Hambraeus. 1996. The influence of physical activity on BMR. Med. Sci. Sports Exerc. 28: 85-91.

Speakman, J. R. and K. R. Westerterp. 2010. Associations between energy demands, physical activity and body composition in adult humans between 18 and 96 y of age. Am. J. Clin. Nutr. 92: 826-834.

Tappy, L. 1996. Thermic effect of food and sympathetic nervous system activity in humans. Reprod Nutr Dev 36: 391-397.

Ten Haaf, T. and P. J. Weijs. 2014. Resting energy-expenditure prediction in recreational athletes of 18-35 years: Confirmation of Cunningham equation and an improved weight-based alternative. PLoS. One 9: e108460.

Valenti G., A.G. Bonomi, K. R. Westerterp. 2016. Quality sleep is associated with overnight metabolic rate in healthy older adults. J Gerontol A Biol Sci Med Sci.

Van Gemert, W. G., K. R. Westerterp, J. M. Greve, and P. B. Soeters. 1998. Reduction of sleeping metabolic rate after vertical banded gastroplasty. Int. J. Obes. 22: 343-348.

Van Hees, V. T., R. C. Van Lummel, and K. R. Westerterp. 2009. Estimating activity-related energy expenditure under sedentary conditions using a tri-axial seismic accelerometer. Obesity 17: 1287-1292.

Westerterp, K. R. 1999. Energy metabolism: Human studies. In: Tarnopolski. M. (ed) Nutritional implications of gender differences in metabolism. CRC Press, Boca Raton, FL: 249-264.

Westerterp, K. R. 2004. Diet induced thermogenesis. Nutr Metab 1: 5.

Westerterp, K. R. 2014. Reliable assessment of physical activity in disease: An update on activity monitors. Cur. Opin. Clin. Nutr. Metab. Care 17: 401-406.

Westerterp, K. R., J. Donkers, E. W. Fredrix, and P. Boekhoudt. 1995. Energy intake, physical activity and body weight: A simulation model. Br. J. Nutr. 73: 337-347.

Weijs, P. J. 2008. Validity of predictive equations for resting energy expenditure in US and Dutch overweight and obese class I and II adults aged 18-65 years. Am. J. Clin. Nutr. 88: 959-970.

Weijs, P. J. and G. A. Vansant. 2010. Validity of predictive equations for resting energy expenditure in Belgian normal weight to morbid obese women. Clin. Nutr. 29: 347-351.

Wouters-Adriaens, M. P. and K. R. Westerterp. 2006. Basal metabolic rate as a proxy for overnight energy expenditure: The effect of age. Br. J. Nutr. 95: 1166-1170.

Wouters-Adriaens, M. P. and K. R. Westerterp. 2008. Low resting energy expenditure in Asians can be attributed to body composition Obesity 16: 2212-2216.

Wulan, S., K. R. Westerterp, and G. Plasqui. 2010. Ethnic differences in body composition and the associated metabolic profile: A comparative study in Asians and Caucasians. Maturitas 65: 315-319. 
Author Query Sheet

Chapter No.: 11

\begin{tabular}{|c|l|l|}
\hline Query No. & \multicolumn{1}{|c|}{ Queries } & Response \\
\hline AQ 1 & Please check if the equation is correct. & OK \\
\hline AQ 2 & $\begin{array}{l}\text { Neelemaat et al. (2013) has been changed to Neelemaat et al. (2012) } \\
\text { as per the reference list. Please check if okay. }\end{array}$ & OK \\
\hline AQ 3 & $\begin{array}{l}\text { Haggerty et al. (1994) has been changed to Haggarty et al. (1994) } \\
\text { as per the reference list. Please check if okay. }\end{array}$ & OK \\
\hline AQ 4 & Please provide page range for Biloft-Jensen et al. (2013). & \\
\hline AQ 5 & Please provide page range for Valenti et al. (2016). & \\
\hline
\end{tabular}

AQ 4: Dec 17;57. doi: 10.3402/fnr.v57i0.21434.

AQ 5: Jun 2. pii: glw107. [Epub ahead of print]

PMID: 27260527 